\title{
Celto-Slavica in Heidelberg
}

\author{
Fadranka Gvozdanović
}

The $8^{\text {th }}$ International Colloquium of the Learned Association Societas CeltoSlavica was held between 1-3 September 2016 at the University of Heidelberg in Germany.

Heidelberg was an old Celtic stronghold. Inhabited since around $5,000 \mathrm{BC}$, the earliest clearly recognisable Urnfield (around 1,200 BC) and early La Tène (since $600 \mathrm{BC}$ ) cultures have been attested on the so-called Holy Hill (Heiligenberg) on the opposite side of the Neckar river, visible on the picture below.

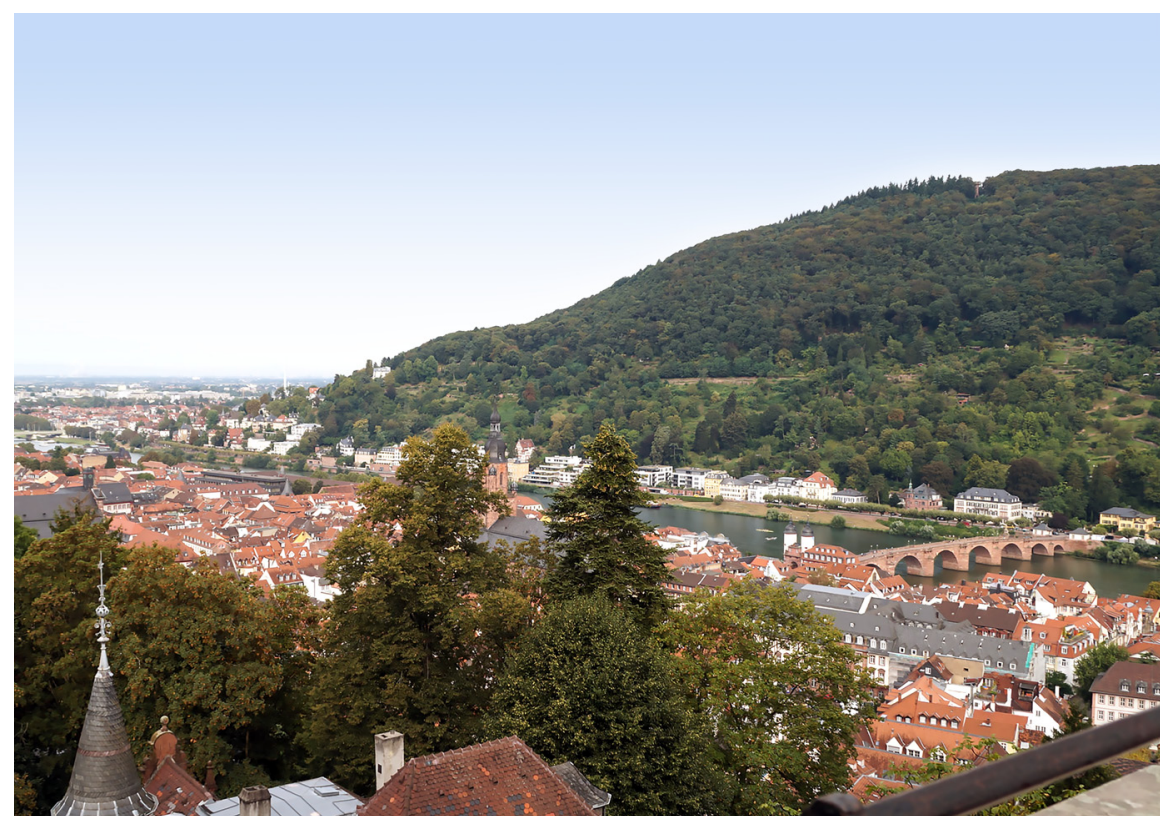

Figure 1. Heidelberg (photo credit: Liza Walther)

The local Celts had a highly developed and steady culture on the Holy Hill, a fact that is demonstrated by an Iron-age well (Bittersbrunnen), ritual sites and remnants of a wall. In the fifth century BC, the Holy Hill was the political centre of the lower Neckar valley. The Celts left the area around 100 BC, when Germanic tribes (especially the Sueben) took over their inhabitation areas. 
The colloquium started with a workshop on archaeogenetic and linguistic evidence about the earliest Celtic migrations. There was a lively discussion about the alternative Near Eastern vs. Steppe hypotheses, for which David Bradley's research group presented new evidence that genetically and chronologically, clearly discernible Celtic ancestors came from the Steppe around four millennia ago. There was also an earlier migration from Near Eastern areas (about seven millennia ago), but Celtic lineage could not be ascertained for this migration. Paul Heggarty of the Jena Institute for the History of Mankind discussed a larger picture of Indo-European migrations, including Indo-Arian, for which linguistic evidence can be plotted even earlier in prehistory. John Koch discussed evidence for early Celtic presence in the Atlantic regions, and Eugenio Lujan presented the newest evidence on Celtiberian based on a project collecting and analysing a relatively complete corpus of the available texts. Tatyana Mikhailova discussed cultural construal of the early Celtic origins, while Václav Blaźek discussed critically the existing methodology for identifying pre-Indo-European substrate elements based on exclusion from the common Proto-Indo-European phonological pattern.

The next two days of the colloquium were dedicated to cultural, linguistic and literary aspects of Celtic traditions. The specific topics included the origins of Celtic languages and language contact, Celtic archaeology and toponymy of Central and South-eastern Europe, historical poetics of Celtic narrative traditions, translations to and from Celtic languages, folklore as a tool for the internal identity construction as well as the medium for the absorption of foreign influences, and teaching of Celtic Studies.

The $8^{\text {th }}$ colloquium of the Societas Celto-Slavica Learned Association has shown again how vital Celtic studies are in the Slavic countries, represented at the event by scholars from Russia, Poland and Czech Republic, fully comparable to the tradition developed in the Celtic lands, including the event delegates from Ireland, both North and South, Wales as well as Brittany.

Professor Jadranka Gvozdanović

Chair, The $8^{\text {th }}$ International Colloquium of Societas Celto-Slavica at the University of Heidelberg 